\title{
BM] Global Health Children and adolescents in African countries should also be vaccinated for COVID-19
}

\author{
Nadia A Sam-Agudu (D) , 1,2,3,4 Nana Kofi Quakyi (D) , 5 Refiloe Masekela (D) ,7 \\ Alimuddin Zumla (D) , 8,9 Jean B Nachega (D) ${ }^{10,11}$
}

To cite: Sam-Agudu NA, Quakyi NK, Masekela R, et al. Children and adolescents in African countries should also be vaccinated for COVID-19. BMJ Global Health 2022;7:e008315. doi:10.1136/ bmjgh-2021-008315

Handling editor Seye Abimbola

Received 16 December 2021 Accepted 4 January 2022

\section{Check for updates}

(c) Author(s) (or their employer(s)) 2022. Re-use permitted under CC BY-NC. No commercial re-use. See rights and permissions. Published by BMJ.

For numbered affiliations see end of article.

\section{Correspondence to} Dr Nadia A Sam-Agudu; nsam-agudu@ihv.umaryland. edu

\section{INTRODUCTION}

Since the onset of the COVID-19 pandemic in December 2019, scientists have worked expediently to develop effective treatments and vaccines for clinical management and prevention of COVID-19. Drugs such as remdesivir, dexamethasone and, more recently, molnupiravir have had modest to impressive results in reducing risk of hospital admission, time to discharge, morbidity and/or mortality. ${ }^{1-3}$

COVID-19 vaccine development and evaluation in clinical trials has been rapid, with safe, effective vaccines being available within 12 months into the pandemic. There are several RNA, DNA, viral vector, inactivated and protein subunit COVID-19 vaccines approved for use. ${ }^{4}$ Table 1 shows the most widely used approved vaccines across each vaccine type. ${ }^{5}$ None of these vaccines are currently manufactured in any African country; however, participants in a few African countries have been enrolled in adult and, more recently, paediatric trials for these vaccines. ${ }^{467}$ Global, equitable access to safe and effective vaccines for all age groups is critical to ending the COVID-19 pandemic.

\section{GLOBAL COVID-19 VACCINE APPROVALS FOR CHILDREN AND ADOLESCENTS}

There is evidence, mostly from high-income countries, to show that children and adolescents under the age of 18 years (hereafter referred to as 'children') can acquire and transmit SARS-CoV-2 infection and experience severe COVID-19, including multisystem inflammatory syndrome in children (MIS-C) and Long COVID-19 syndrome. ${ }^{8-10}$ Globally, children under 5 years of age represent only $2 \%$ of reported COVID- 19 cases and $0.1 \%$ of deaths, whereas 5-14year-olds represent $7 \%$ and $0.1 \%$, and $15-24$ year-olds represent $15 \%$
Summary box

Available evidence indicates that children and adolescents can transmit SARS-CoV-2 infection and are also vulnerable to severe disease and death.

- There has been recent acceleration in approvals, initiation and scale-up of COVID-19 vaccination among children under 18 years in high-, low- and middleincome countries around the world.

- Current data indicate that children in African countries also experience COVID-19-related morbidity and mortality, which may be worse than that of their counterparts in other regions of the world.

- In this article, we outline the global status quo on scale-up of safe and effective COVID-19 vaccines for younger populations, and make an argument for why African children and adolescents should also be targeted for vaccination.

and $0.4 \%$ of cases and deaths, respectively. ${ }^{8}$ However, available data indicate that infants under 1 year of age have disproportionately high mortality, ${ }^{10}$ and adolescents and young people are increasingly representing higher proportions of the COVID-19 case load. $^{11}$ Currently, six widely used COVID-19 vaccines have received emergency use authorisation or full approval for children under 18 years of age in at least one country ${ }^{12-19}$ (table 1 ). These include the USA's Pfizer-BioNTech and Moderna (approved outside the USA) vaccines for adolescents $\geq 12$ years of age, ${ }^{12} 14$ Pfizer-BioNTech vaccine for 5 - 11 year-olds, ${ }^{13}$ China's Sinovac and Sinopharm vaccines for 3-17 year-olds ${ }^{16} 18$ and India's Covaxin for children as young as 2 years old ${ }^{15}$ (table 1 ). At the time of writing, full vaccination is considered as receiving the one (Johnson and Johnson) or two dose (all others) primary series of currently available first generation COVID-19 vaccines. ${ }^{20}$ To date, 10 vaccines have been approved by the WHO for emergency use listing in adults, ${ }^{21}$ six of which have 
Table 1 Major COVID-19 vaccines approved by at least one country, and paediatric age indications*

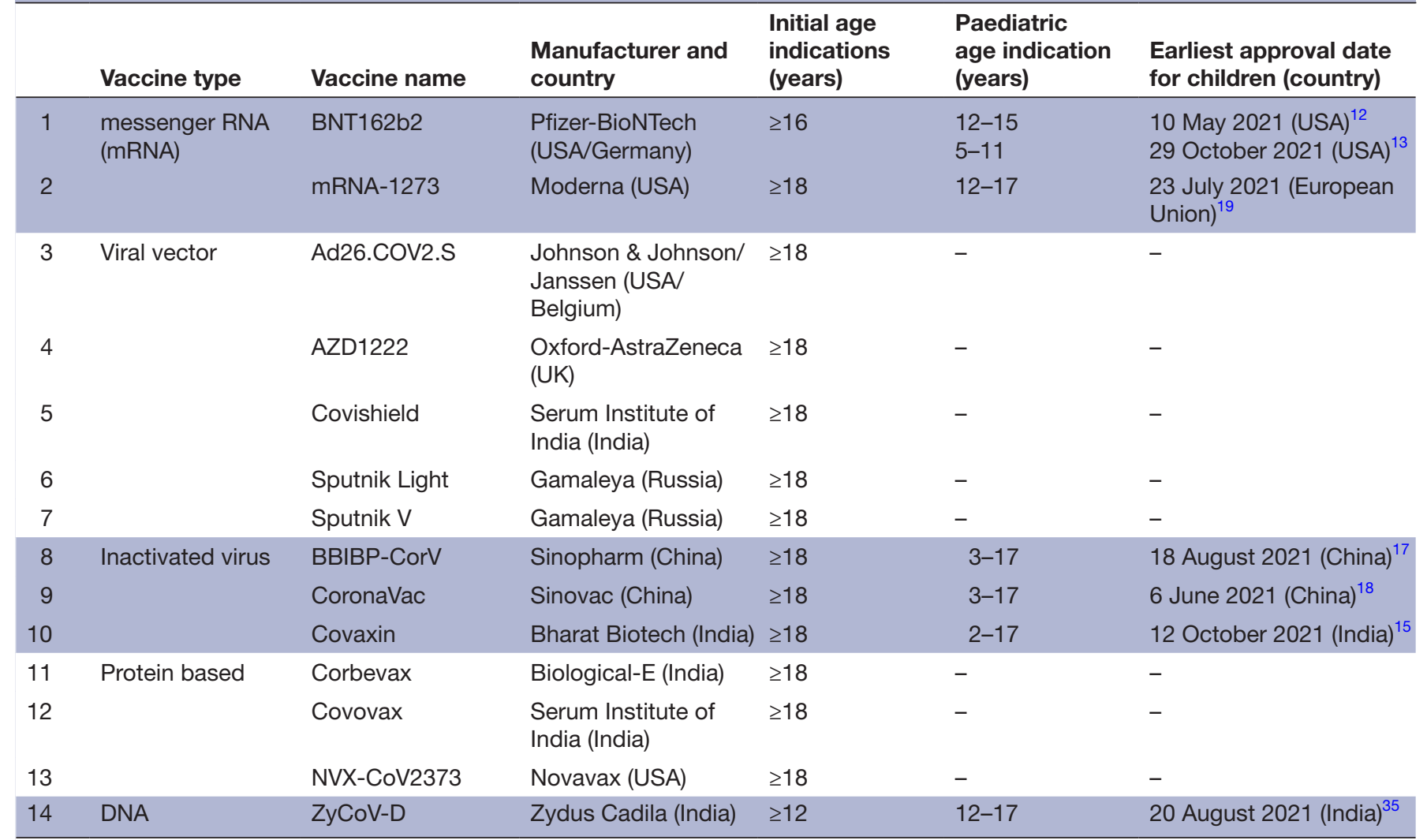

*As of 14 January 2022.

approval for paediatric indication in at least one country (tables 1 and 2). Consequently, COVID-19 vaccine coverage for children is rising in some countries; in the USA, for example, $53 \%$ of $12-17$ year-olds were fully vaccinated and $25 \%$ of $5-11$ year-olds were partially vaccinated by early January 2022. ${ }^{22}$ By that same time point, population-wide full vaccination rates in high-income countries have reached approximately $60 \%-90 \%,{ }^{4}$ and third dose boosters are being scaled up for adults and more recently, adolescents 12 years and older in some countries. $^{23}$

\section{THE CASE FOR COVID-19 VACCINATION AMONG CHILDREN IN AFRICAN COUNTRIES}

As has been for adults, the COVID-19 vaccination situation is quite different for children in African countries, vis-à-vis globally. Currently, most of the countries with the highest rates of full COVID-19 vaccination in Africa are island nations or in Northern Africa, for example, the Seychelles $(79 \%)$, Mauritius $(72 \%)$, Morocco $(62 \%)$, Tunisia $(50 \%)$ and Cabo Verde $(46 \%){ }^{4}$ In a recent position statement, the WHO acknowledges that the majority of evidence in COVID-19 among children is from high-income countries, and recommends that "countries should consider the individual and population benefits of immunizing children and adolescents in their specific epidemiological and social context when developing their COVID-19 immunization policies and programs. 8 This recommendation thus puts the onus on countries to conduct their own local research to guide decision-making on paediatric COVID-19 vaccination policy. Steep inequity in access to vaccines and low rates of vaccination in high-risk adult populations need to be considered vis-à-vis vaccinating overall lower risk paediatric populations in Africa. However, benefits to vaccinating children include minimising school closures, the academic and psychological impacts of disruptions in education and intergenerational transmission. ${ }^{82}$ Moreover, children in African countries also bear high burdens of both communicable (eg, HIV, tuberculosis) and non-communicable diseases (eg, sickle cell disease, asthma), which would render them at risk for higher morbidity and mortality if coinfected with SARSCoV-2. ${ }^{24}$ To date, only 11 African countries have approved COVID-19 vaccination among children under 18 years of age $^{25}$ (table 2 and figure 1 ).

The African Forum for Research and Education in Health (AFREhealth) COVID-19 Research Collaboration on Children and Adolescents recently published results of a retrospective study conducted in six African countries. This study included 469 children and adolescents aged 3 months to 19 years hospitalised between March and December 2020 in East (Kenya, Uganda), West (Ghana, Nigeria), Central (Democratic Republic of the Congo) and Southern Africa (South Africa). ${ }^{26}$ Approximately $25 \%$ of children presented with comorbidities; $3.8 \%$ were suspected or confirmed to have MIS-C, and 39 (8.3\%) died in hospital. Among 
Table 2 African countries that have approved COVID-19 vaccination for children and adolescents*

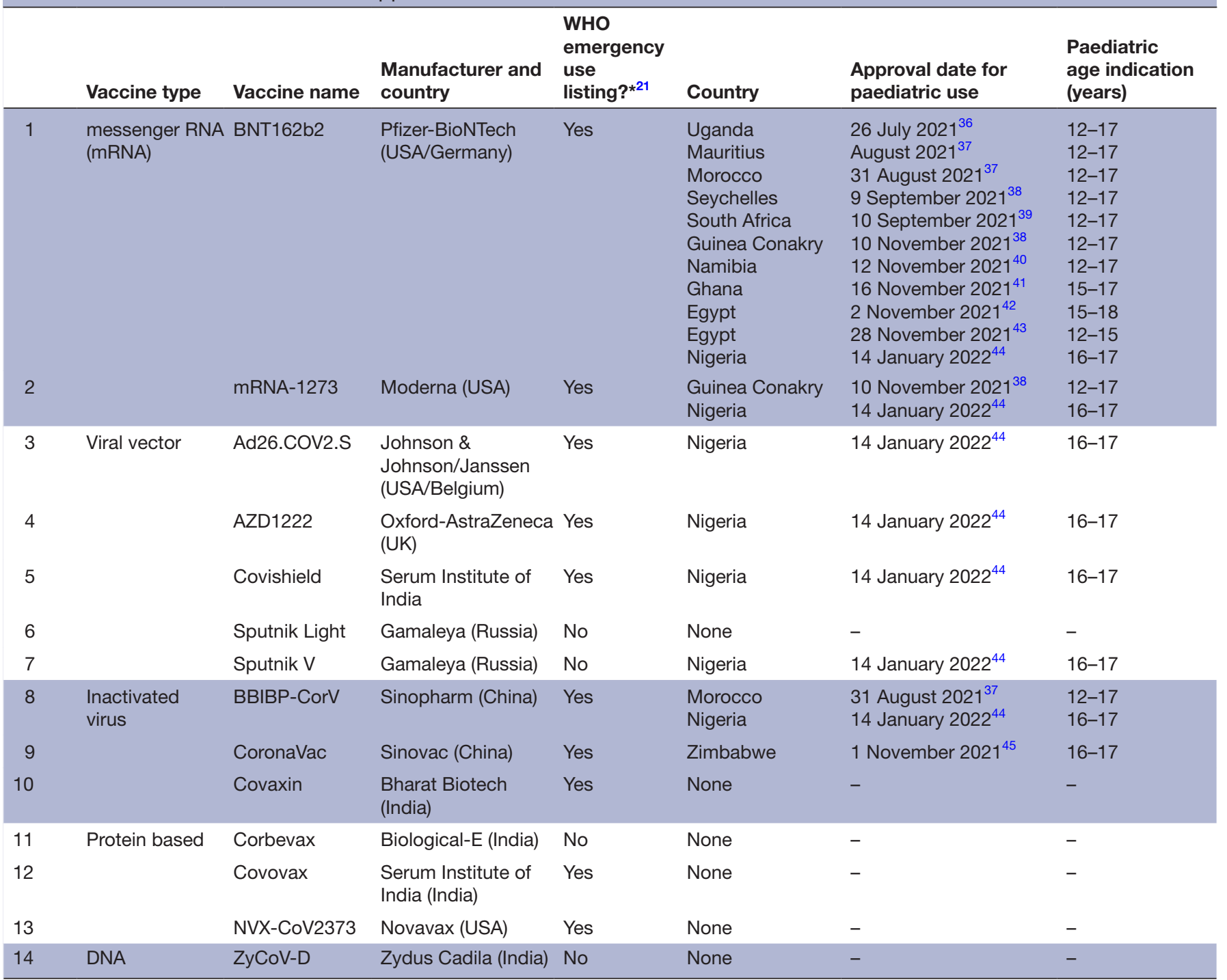

${ }^{*}$ As of 14 January 2022.

†Waiver granted for 16 and 17 year-olds to get any available COVID-19 vaccine if needed for educational (e.g school vaccine mandate, international institution admission/attendance requirements) and international travel purposes. Approvals in table indicated for vaccines currently available in Nigeria. $^{4}$

the children who died were $22(32 \%)$ of the 69 children admitted to the intensive care unit (ICU), and 4 $(22 \%)$ of the 18 with suspected/confirmed MIS-C. ${ }^{26}$ In multivariable ordinal logistic regression, factors independently associated with severe outcomes (oxygen requirement, ICU admission, mechanical ventilation and death) were age <1 year, hypertension, chronic lung disease and haematological disorders. ${ }^{26}$

This new evidence helps to address a pressing need for data to guide policy and practice for COVID-19 in African countries. ${ }^{27}$ The AFREhealth study provides multicountry, multiregional evidence of relatively high mortality rates among hospitalised children with COVID-19. Mortality in the AFREhealth study was $8.3 \%,{ }^{26}$ severalfold higher than paediatric case fatality rates of $0.24 \%$ (in low and middleincome countries) and $0.01 \%$ (in high-income countries) reported in a systematic review by Kitano et $a l^{10}$ and still higher than the global average of $0.1 \%-0.4 \%$ reported by the WHO. ${ }^{8}$

The wide differences seen in paediatric COVID-19 case fatality rates between lower resource African settings and high-resource settings have also been seen among adults, as demonstrated by the high $(\sim 50 \%)$ mortality among critically ill adult patients with COVID-19 in the African COVID-19 Critical Care Outcomes Study. ${ }^{28}$ These findings infer the significant role that health infrastructure-or lack thereof-plays in modulating COVID-19 case fatality rates beyond the pathogenicity of circulating SARS-CoV-2 strains. The emerging evidence supports our call for African countries-especially those with the least resourced health infrastructure-to prioritise disease prevention and galvanise efforts to scale up COVID-19 vaccine supply and uptake, including among children. With 


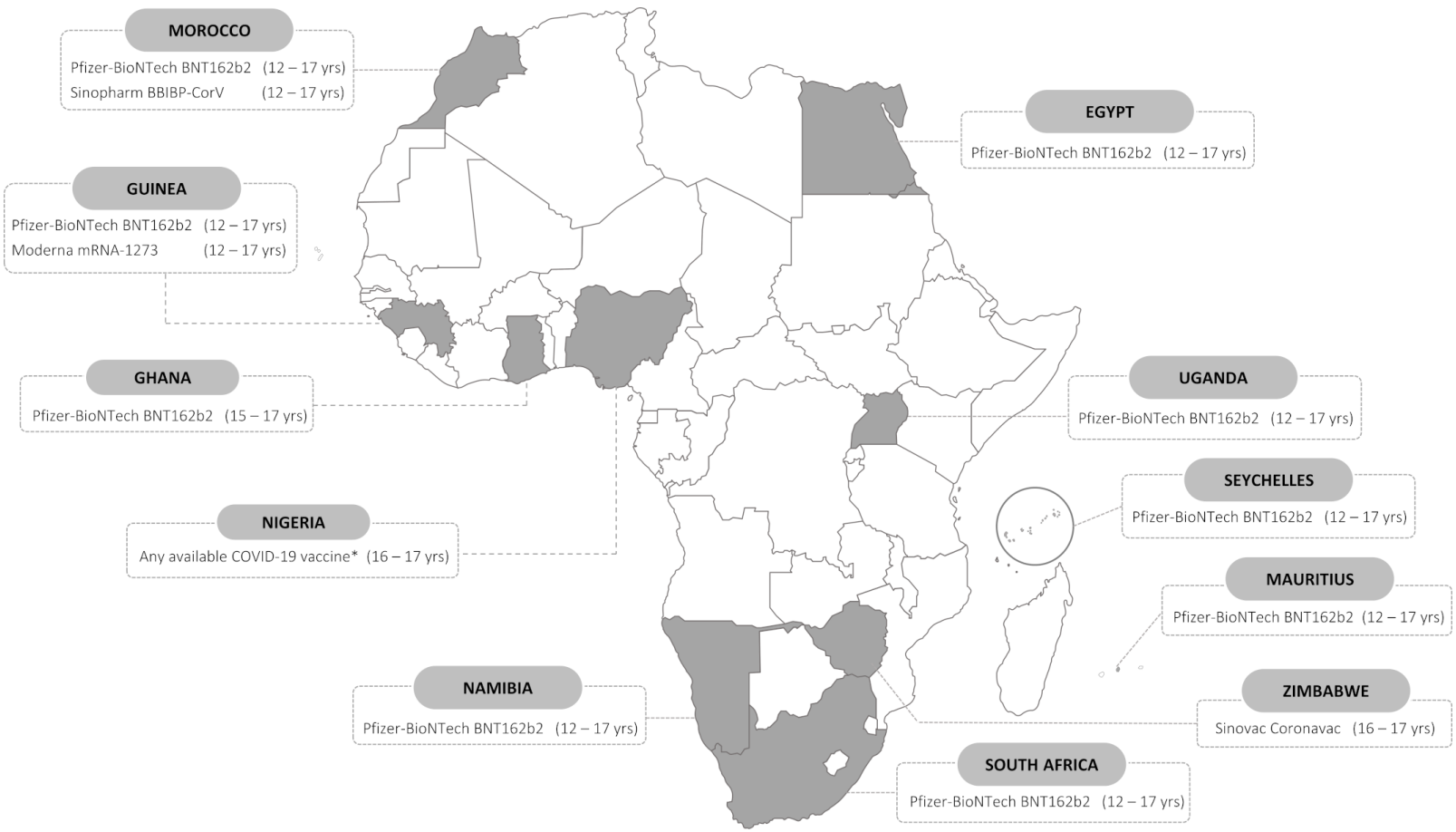

Figure 1 African countries with local approval for paediatric COVID-19 vaccination, age indications and vaccine types approved. Data as of 14 January 2022. * Nigeria has granted waivers for 16 and 17 year olds to receive any COVID-19 vaccines available at vaccination centers, for educational and international travel purposes. See table 2 for details.

its relatively young population, the African continent cannot achieve herd immunity without vaccinating children.

\section{CONSIDERATIONS FOR INCLUSION OF CHILDREN AND ADOLESCENTS IN VACCINE POLICY ACROSS AFRICA}

While a case may be made for children to receive COVID-19 vaccines, policy making for African countries has to be made in consideration of unacceptably low adult vaccination rates in the setting of global inequities in accessing vaccines, poor risk communication and under-resourced health systems. As of 8 January 2022, full COVID-19 vaccine coverage across Africa was $9.6 \%$, with approximately $52 \%$ of countries still below $10 \%$ coverage. ${ }^{29}$ Clearly, the WHO's modest targets of $40 \%$ full vaccine coverage for all countries by the end of 2021 was not met, and the $70 \%$ target for June $2022^{30}$ will likely not be attained for much of the continent. The emergence of the SARS-CoV-2 Omicron variant, first reported to WHO by South Africa on 24 November $2021,{ }^{31}$ is likely to further delay the achievement of these targets by potentially redefining 'full coverage' in necessitating boosters for adequate protection. $^{32}$ As of 13 January 2022, thirty African countries had detected Omicron, out of 142 countries reporting this new variant globally. ${ }^{33}$

To date, only a few African countries have approved paediatric COVID-19 vaccination, thus vaccine roll-out for children will continue to lag behind that of adults for much of the continent. For children who may not be targeted for vaccination at the same time as the rest of the population, at a minimum, we propose prioritisation similar to that for adults early in vaccine roll-out: those at highest risk of severe disease and death, and older adolescents (who are more likely to transmit infection) ${ }^{8}$ living with high-risk adults should also receive vaccines. Thus, high-risk children in African countries should be prioritised for COVID-19 vaccination regardless of their age; this population includes children with hypertension, chronic lung disease and haematological disorders, as reported by the AFREhealth study. ${ }^{26}$ Paediatric COVID-19 vaccination can be prioritized using risk stratifications according to presence and number of comorbidities, and cohabitation or close contact with high-risk adults. Likewise, healthy adults living with and/or caring for high-risk children should also be encouraged to get vaccinated; this includes healthcare workers. Our recommendations are in line with an analysis from the Africa Centres for Disease Control and Prevention, which indicates that reaching $70 \%$ vaccine coverage for nearly all African countries will require inclusion and vaccination of children at least 10 years of age. ${ }^{34}$

\section{CONCLUSION}

New, locally generated evidence indicates that COVID19-related morbidity and mortality among children and adolescents in African countries may be much higher than among their counterparts in other regions of the world. The advent of the rapidly spreading Omicron variant and its as-yet unknown impact across Africa and among children is of additional concern. It is important to scale up the generation of rigorous local evidence across Africa through collection and reporting of national-level, age-disaggregated epidemiological data and the design and implementation of observational and interventional studies focused on 
paediatric COVID-19. Vaccination with currently available vaccines continues to be recommended for the eligible who can access them. Given the emerging evidence of paediatric vulnerability to severe COVID-19, it is imperative that policy makers and public health institutions include African children in their COVID-19 vaccine guidelines and procurement planning, especially for those at highest risk of severe disease and death. While COVID-19 vaccines are a gamechanging public health tool, until the pandemic is under epidemic control, basic infection control methods such as mask wearing, hand sanitisation, good indoor ventilation, and physical distancing must be concurrently observed.

\author{
Author affiliations \\ ${ }^{1}$ International Research Center of Excellence, Institute of Human Virology Nigeria, \\ Abuja, Nigeria \\ ${ }^{2}$ Institute of Human Virology, University of Maryland School of Medicine, Baltimore, \\ Maryland, USA \\ ${ }^{3}$ Department of Pediatrics, University of Maryland School of Medicine, Baltimore, \\ Maryland, USA \\ ${ }^{4}$ Department of Paediatrics and Child Health, University of Cape Coast School of \\ Medical Sciences, Cape Coast, Ghana \\ ${ }^{5}$ International Projects Unit, The Aurum Institute, Accra, Ghana \\ ${ }^{6}$ Department of Health Policy and Management, New York University School of \\ Global Public Health, New York, New York, USA \\ ${ }^{7}$ Department of Paediatrics and Child Health, College of Health Sciences, University \\ of KwaZulu Natal, Durban, KwaZulu Natal, South Africa \\ ${ }^{8}$ Division of Infection and Immunity, University College London Medical School, \\ London, UK \\ ${ }^{9} \mathrm{NIHR}$ University College London Hospitals Biomedical Research Centre, London, UK \\ ${ }^{10}$ Center for Global Health, University of Pittsburgh, Pittsburgh, Pennsylvania, USA \\ ${ }^{11}$ Center for Infectious Diseases, Stellenbosch University Faculty of Medicine and \\ Health Sciences, Cape Town, Western Cape, South Africa
}

Twitter Nadia A Sam-Agudu @NASAdoc, Nana Kofi Quakyi @nkquakyi, Refiloe Masekela @bronchigirl and Alimuddin Zumla @AliZumla

Acknowledgements NAS-A acknowledges support from US National Institutes of Health (NIH) National Institute of Child Health and Human Development grant \#R01HD089866 (Adolescent to Adult Patient-Centered HIV Transition, Nigeria), and $\mathrm{NIH} \mathrm{Fogarty} \mathrm{International} \mathrm{Center} \mathrm{(FIC)} \mathrm{award} \mathrm{through} \mathrm{the} \mathrm{Adolescent} \mathrm{HIV} \mathrm{Prevention}$ and Treatment Implementation Science Alliance (AHISA), for the Central and West Africa Implementation Science Alliance (CAWISA). Sir Prof. AZ acknowledges support from the European Union EDCTP-funded PANDORA-ID-NET, the Central African Network on Tuberculosis, HIV/AIDS and Malaria (CANTAM-3); and the East Africa Consortium for Clinical Research (EACCR-3). AZ is a Mahathir Foundation Science Award and Pascoal Mocumbi Prize laureate. JBN is supported by NIH/FIC grants 1R25TW011217-01 (African Association for Health Professions Education and Research); 1R21TW011706-01 (Cardiometabolic Outcomes, Mechanisms, and Approach to Prevention of Dolutegravir Associated Weight Gain in South Africa); and 1D43TW010937-01A1 (University of Pittsburgh HIV Comorbidities Research Training Program in South Africa); as well as NIH/NIAID grant No. U01 Al096299 (Central Africa-International epidemiology to Evaluate AIDS (CA-leDEA).

Contributors NAS-A and JBN conceptualised the manuscript. NAS-A and NKQ drafted the manuscript and collated the data. All coauthors provided substantial contributions in terms of critical revision of the draft, and reviewed as well as approved the final version submitted for publication.

Funding US National Institutes of Health/Fogarty International Center Grant No. 1R25TW011217-01 to the African Forum for Research and Education in Health (AFREhealth); Principal Investigators: Prisca Adejumo, Jean B. Nachega, Nelson K. Sewankambo, and Fatima Suleman.

Map disclaimer The inclusion of any map (including the depiction of any boundaries therein), or of any geographic or locational reference, does not imply the expression of any opinion whatsoever on the part of BMJ concerning the legal status of any country, territory, jurisdiction or area or of its authorities. Any such expression remains solely that of the relevant source and is not endorsed by BMJ. Maps are provided without any warranty of any kind, either express or implied.
Competing interests None declared.

Patient consent for publication Not required.

Ethics approval This study does not involve human participants.

Provenance and peer review Not commissioned; internally peer reviewed.

Data availability statement All data relevant to the study are included in the article.

Open access This is an open access article distributed in accordance with the Creative Commons Attribution Non Commercial (CC BY-NC 4.0) license, which permits others to distribute, remix, adapt, build upon this work non-commercially, and license their derivative works on different terms, provided the original work is properly cited, appropriate credit is given, any changes made indicated, and the use is non-commercial. See: http://creativecommons.org/licenses/by-nc/4.0/.

\section{ORCID iDs}

Nadia A Sam-Agudu http://orcid.org/0000-0001-5052-7730

Nana Kofi Quakyi http://orcid.org/0000-0002-1483-4001

Refiloe Masekela http://orcid.org/0000-0002-2006-1201

Alimuddin Zumla http://orcid.org/0000-0002-5111-5735

Jean B Nachega http://orcid.org/0000-0002-2862-4443

\section{REFERENCES}

1 Beigel JH, Tomashek KM, Dodd LE, et al. Remdesivir for the Treatment of Covid-19 - Final Report. N Engl J Med 2020;383:1813-26.

2 RECOVERY Collaborative Group, Horby P, Lim WS, et al. Dexamethasone in hospitalized patients with Covid-19. N Engl $\mathrm{J}$ Med 2021;384:693-704.

3 Merck. Merck and Ridgeback's Investigational Oral Antiviral Molnupiravir Reduced the Risk of Hospitalization or Death by Approximately 50 Percent Compared to Placebo for Patients with Mild or Moderate COVID-19 in Positive Interim Analysis of Phase 3 Study, 2021. Available: https://www.merck.com/news/merckand-ridgebacks-investigational-oral-antiviral-molnupiravir-reducedthe-risk-of-hospitalization-or-death-by-approximately-50-percentcompared-to-placebo-for-patients-with-mild-or-moderat/ [Accessed 2 Dec 2021].

4 McGill University COVID19 Vaccine Tracker Team. COVID-19 vaccine tracker. Available: https://covid19.trackvaccines.org/ [Accessed 8 Jan 2022].

5 Mallapaty S. China's COVID vaccines have been crucial - now immunity is waning. Nature 2021;598:398-9.

6 Makoni M. COVID-19 vaccine trials in Africa. Lancet Respir Med 2020;8:e79-80.

7 Hagan Jr. JE, Ahinkorah BO, Seidu A-A, et al. Africa's preparedness towards COVID-19 vaccines: Demand and acceptability challenges. Curr Res Behav Sci 2021;2:100048.

8 World Health Organization. Interim statement on COVID-19 vaccination for children and adolescents, 2021. Available: https:// www.who.int/news/item/24-11-2021-interim-statement-on-covid19-vaccination-for-children-and-adolescents [Accessed 2 Dec 2021].

9 Li B, Zhang S, Zhang R, et al. Epidemiological and clinical characteristics of COVID-19 in children: a systematic review and meta-analysis. Front Pediatr 2020;8.

10 Kitano T, Kitano M, Krueger C, et al. The differential impact of pediatric COVID-19 between high-income countries and low- and middle-income countries: a systematic review of fatality and ICU admission in children worldwide. PLoS One 2021;16:e0246326.

11 World Health Organization. WHO coronavirus disease (COVID-19) Dashboard, data table, and detailed surveillance data, 2022. Available: https://covid19.who.int/ [Accessed 8 Jan 2022]

12 US Food and Drug Administration. Coronavirus (COVID-19) update: FDA Authorizes Pfizer-BioNTech COVID-19 vaccine for emergency use in adolescents in another important action in fight against pandemic, 2021. Available: https://www.fda.gov/news-events/pressannouncements/coronavirus-covid-19-update-fda-authorizes-pfizerbiontech-covid-19-vaccine-emergency-use [Accessed 2 Dec 2021].

13 US Food and Drug Administration. FDA Authorizes Pfizer-BioNTech COVID-19 vaccine for emergency use in children 5 through 11 years of age, 2021. Available: https://www.fda.gov/news-events/pressannouncements/fda-authorizes-pfizer-biontech-covid-19-vaccineemergency-use-children-5-through-11-years-age [Accessed 2 Dec 2021]. 
14 Reuters. Philippines approves emergency use of Moderna's COVID-19 vaccine for 12-17 year olds, 2021. Available: https://www. reuters.com/world/asia-pacific/philippines-approves-emergencyuse-modernas-covid-19-vaccine-12-17-year-olds-2021-09-03/ [Accessed 2 Dec 2021]

15 NDTV All India. Covaxin shot recommended for children in India, 2021. Available: https://www.ndtv.com/india-news/covaxinrecommended-by-expert-panel-for-children-from-2-to-18-years2572694\#pfrom=home-ndtv_topscroll [Accessed 2 Dec 2021].

16 The Guardian. Hong Kong authorises Sinovac Covid vaccine for children aged 3 to 17, 2021. Available: https://www.theguardian. com/world/2021/nov/20/hong-kong-authorises-sinovac-covidvaccine-for-children-aged-3-to-17 [Accessed 2 Dec 2021]

17 Global Times. China approves emergency use of Sinopharm COVID-19 vaccine for children aged 3-17, 2021. Available: https:// www.globaltimes.cn/page/202108/1231842.shtml [Accessed 8 Dec 2021].

18 The Tribune. China authorises CoronaVac Covid-19 vaccine for children above 3 years, 2021. Available: https://www.tribuneindia. $\mathrm{com} /$ news/world/china-authorises-coronavac-covid-19-vaccine-forchildren-above-3-years-264369 [Accessed 8 Dec 2021].

19 European Medicines Agency. COVID-19 vaccine Spikevax Approved for children aged 12 to 17 in EU, 2021. Available: https://www.ema. europa.eu/en/news/covid-19-vaccine-spikevax-approved-childrenaged-12-17-eu [Accessed 8 Dec 2021].

20 World Health Organization. COVID-19 vaccine Tracker and landscape, 2022. Available: https://www.who.int/publications/m/ item/draft-landscape-of-covid-19-candidate-vaccines [Accessed 8 Jan 2022].

21 World Health Organization. Regulation and Prequalification: Emergency Use Listing (EUL)-COVID-19 Vaccines, 2022. Available: https://www.who.int/teams/regulation-prequalification/eul/covid-19 [Accessed 14 Jan 2022].

22 American Academy of Pediatrics. Children and COVID-19 vaccinations trends, 2022. Available: https://www.aap.org/en/pages/ 2019-novel-coronavirus-covid-19-infections/children-and-covid-19vaccination-trends/ [Accessed 8 Jan 2022].

23 US Centers for Disease Control and Prevention. COVID-19 vaccine booster Shots, 2022. Available: https://www.cdc.gov/coronavirus/ 2019-ncov/vaccines/booster-shot.html [Accessed 8 Jan 2022].

24 Coker M, Folayan MO, Michelow IC, et al. Things must not fall apart: the ripple effects of the COVID-19 pandemic on children in subSaharan Africa. Pediatr Res 2021;89:1078-86.

25 Africa Centres for Disease Control. COVID-19 scientific and public health policy Update-24 November 2021, 2021. Available: https:// africacdc.org/download/covid-19-scientific-and-public-healthpolicy-update-24-november-2021/\# [Accessed 3 Dec 2021].

26 Nachega JB, Sam-Agudu NA, Machekano RN, et al. Assessment of clinical outcomes among children and adolescents hospitalized with COVID-19 in 6 sub-Saharan African countries. JAMA Pediatr 2022. doi:10.1001/jamapediatrics.2021.6436. [Epub ahead of print: 19 Jan 2022].

27 Sam-Agudu NA, Rabie H, Pipo MT, et al. The critical need for pooled data on coronavirus disease 2019 in African children: an AFREhealth call for action through multicountry research collaboration. Clin Infect Dis 2021;73:1913-9.

28 African COVID-19 Critical Care Outcomes Study (ACCCOS) Investigators. Patient care and clinical outcomes for patients with COVID-19 infection admitted to African high-care or intensive care units (ACCCOS): a multicentre, prospective, observational cohort study. Lancet 2021;397:1885-94.

29 WHO AFRO Region. Africa COVID-19 Dashboard, 2022. Available: https://app.powerbi.com/view?r=eyJrljoiY2ViYzlyZjltYzhkMiO0ZWVk LTgyM2ItZTk1ZTJmODRjMTkxliwidCI6ImY2MTBjMGI3LWJkMjQt NGIzOS04MTBiLTNkYZI4MGFmYjU5MCIsImMiOjh9 [Accessed 8 Jan 2022].
30 World Health Organization. Strategy to achieve global COVID-19 vaccination by mid-2022, 2021. Available: https://cdn.who.int/ media/docs/default-source/immunization/covid-19/strategy-toachieve-global-covid-19-vaccination-by-mid-2022.pdf?sfvrsn= 5a68433c_5 [Accessed 8 Dec 2021].

31 World Health Organization. Classification of omicron (B.1.1.529): SARS-CoV-2 variant of concern, 2021. Available: https://www.who. int/news/item/26-11-2021-classification-of-omicron-(b.1.1.529)sars-cov-2-variant-of-concern [Accessed 13 Dec 2021].

32 Petersen E, Ntoumi F, Hui DS, et al. Emergence of new SARS-CoV-2 Variant of Concern Omicron (B.1.1.529) - highlights Africa's research capabilities, but exposes major knowledge gaps, inequities of vaccine distribution, inadequacies in global COVID-19 response and control efforts. Int J Infect Dis 2022;114:268-72.

33 AFRO Region WHO. Omicron-fuelled COVID-19 surge in African plateaus, 2022. Available: https://www.afro.who.who.int/news/ omicron-fuelled-covid-19-surge-africa-plateaus? $s=08$

34 Africa Centers for Disease Control and Prevention. Vaccine Advocacy Infographics: What age groups do AU Member States need to target to reach 70\% COVID-19 vaccination coverage? 2021. Available: https://africacdc.org/download/vaccination-advocacyinfographics/\# [Accessed 13 Dec 2021].

35 The Tribune. India gets its 1st vaccine for children above 12; Zydus's 3-dose ZyCoV-D approved, 2021. Available: https:// www.tribuneindia.com/news/nation/india-gets-its-1st-vaccinefor-children-above-12-zyduss-3-dose-zycov-d-approved-299874 [Accessed 8 Dec 2021].

36 Xinhuanet News. Uganda to start inoculating children under 15 with Pfizer vaccine, 2021. Available: http://www.xinhuanet.com/english/ africa/2021-07/26/c_1310086931.htm [Accessed 8 Dec 2021].

37 Bloomberg. Mauritius orders Covid-19 doses to cover remaining population, 2021. Available: https://www.bloomberg.com/news/ articles/2021-07-27/mauritius-orders-covid-19-doses-to-coverremaining-population [Accessed 14 Jan 2022]

38 Seychelles News Agency. Vaccination campaign for Seychellois children begins Friday, 2021. Available: http://www. seychellesnewsagency.com/articles/15457/Naccination+campaign+ for+Seychellois+children+begins+Friday [Accessed 14 Jan 2022]

39 South African Health Products Regulatory Authority. SAHPRA update on section 21 Authorisation for Pfizer Comirnaty vaccine, 2021. Available: https://www.sahpra.org.za/press-releases/sahpraupdate-on-section-21-authorisation-for-pfizer-comirnaty-vaccine/ [Accessed 8 Dec 2021].

40 Xinhuanet News. Namibia to start vaccinating teens against COVID-19, 2021. Available: http://www.news.cn/english/africa/2021 11/12/c_1310307551.htm [Accessed 8 Dec 2021].

41 Graphic Online. Ghana: FDA authorizes Pfizer vaccine for 15 to 17-year-olds, 2021. Available: https://www.graphic.com.gh/news/ general-news/ghana-fda-authorizes-pfizer-vaccine-for-15-17-yearolds.html [Accessed 8 Dec 2021].

42 Egypt Today. Egypt to vaccinate children aged between 15, 18 against COVID-19, 2021. Available: https://www.egypttoday.com/ Article/1/109479/Egypt-to-vaccinate-children-aged-between-15-18against-COVID [Accessed 8 Dec 2021].

43 Reuters. Egypt authorizes Pfizer's COVID-19 vaccine for 12 to 15 year-olds, 2021. Available: https://www.reuters.com/world/africa/ egypt-authorizes-pfizers-covid-19-vaccine-12-15-year-olds-202111-28/ [Accessed 8 Dec 2021].

44 The Cable Nigeria. NPHCDA: 16-year-olds can receive COVID vaccine if required for educational purposes, 2022. Available: https:// www.thecable.ng/nphcda-16-year-olds-can-receive-covid-vaccineif-required-for-educational-purposes [Accessed 14 Jan 2022]

45 VOA News. Zimbabwe starts vaccinating teens against COVID-19, 2021. Available: https://www.voanews.com/a/zimbabwe-startsvaccinating-teens-against-covid-19/6297089.html [Accessed 8 Dec 2021]. 